\title{
Report Case: Alveolar Microlithiasis
}

\author{
F. Jaafari ${ }^{1 *}$, B. Bannar ${ }^{1}$, B. Boutakioute ${ }^{1}$, M. Ouali Idrissi ${ }^{1}$, N. Cherif Idrissi Ganouni ${ }^{1}$
}

${ }^{1}$ Radiology Department, ARRAZI Hospital, CHU Mohammed VI, Cadi Ayad University, Marrakech, Morocco

DOI: $10.36347 /$ simcr.2021.v09i03.018

| Received: 28.02.2021 | Accepted: 16.03.2021 | Published: 17.03.2021

*Corresponding author: Fadwa Jaafari

\section{Abstract}

Alveolar microlithiasis (AMP) is a rare genetic disease characterized by intra-alevolar phosphate and calcim deposition in the pulmonary parenchyma in a sparse bilateral manner with a predominance in the lower and middle regions. This disease results from a genetic dysfunction characterized by inactivating mutations in the SLC34A2 gene resulting in local intra-alveolar phosphate aggregation due to sodium-dependent phosphate co-transporter deficiency. Patients with this disease are usually seen in late stages with a chronic pulmonary heart and hypoxemia. High resolution chest CT scan with chest x-ray make it possible to diagnose this disease with a pathognomonic appearance in the form of diffuse calcified micronodules. Only lung transplantation has been shown to be effective as a treatment for the disease. We describe the case of a 58-year-old woman with a history of pulmonary tuberculosis treated in 1994 and siblings treated for undocumented pneumonia, referred to our department for a chest scan and presenting with NYHA stage III dyspnea and greenish sputum. Imaging was suggestive of extensive bilateral interstitial lung disease.

Keywords: Calcification, interstitial lung disease, microliths, pulmonary alveolar microlithiasis.

Copyright $\odot 2021$ The Author(s): This is an open-access article distributed under the terms of the Creative Commons Attribution 4.0 International License (CC BY-NC 4.0) which permits unrestricted use, distribution, and reproduction in any medium for non-commercial use provided the original author and source are credited.

\section{INTRODUCTION}

Alveolar microlithiasis (AMP) is a rare genetic disease characterized by intra-alevolar phosphate and calcim deposition in the pulmonary parenchyma in a sparse bilateral manner with a predominance in the lower and middle regions. This disease results from a genetic dysfunction characterized by inactivating mutations in the SLC34A2 gene resulting in local intraalveolar phosphate aggregation due to sodiumdependent phosphate co-transporter deficiency [1]. The disease has a slight female predominance in the familial form [2]. The majority of reported cases were from Europe and Asia [1]. Patients with this disease are usually seen in late stages with a chronic pulmonary heart and hypoxemia. High resolution chest CT scan with chest $\mathrm{x}$-ray make it possible to diagnose this disease with a pathognomonic appearance in the form of diffuse calcified micronodules, generally there is no radiocilinic discordance [3].

\section{Case Report}

A 58 year women, housewife, was referred to the radiology department for Chest CT, on clinical management of his progressive shortness of breath and stage III dyspnea of NYHA and greenish expectorations the last 12 months. In terms of medical history, she mentioned that she was treated for pulmonary tuberculosis in 1994 with no document, also occasional left-sided pleuritic chest pain with no other exercise related pain, no peripheral swelling, no weight loss and no night sweats. She is a non-smoker, with no exposure to birds or pets, she does not have any allergies and she has no history of tuberculosis. With reference to the family history, siblings treated for undocumented pneumopathy. On physical examination her heart rate was $90 \mathrm{bpm}$, blood pressure was $100 / 60 \mathrm{mmHg}$ and a respiratory rate of 22 breaths/minute, there were marked discrete inspiratory crackles. Pulmonary examination findings are sounds like rhonchi at the bases, sand there was no edema, ascites or hepato splenomegalia. A high resolution computed tomography of the chest (Fig-1) was performed and revealed several calcifications throughout the parenchyma, partially calcified para pleural and para mediastinal line, sub-pleural cystic changes and calcified interlobular septa. Considering the findings on the CT scan and her history, her case was discussed and the patient was diagnosed with alveolar microlithiasis. 


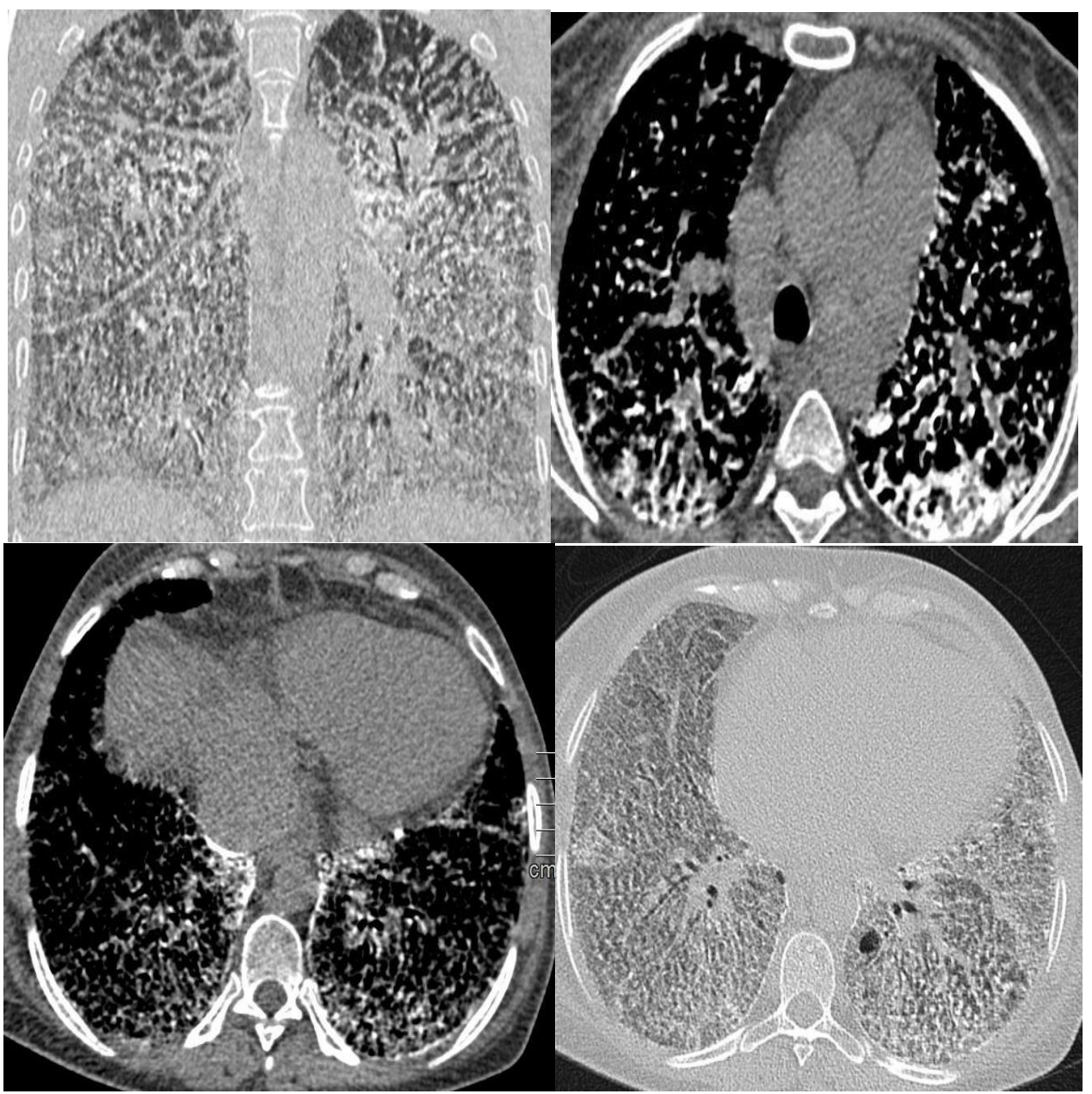

Fig-1: High resolution computed tomography (HRCT) of the chest revealing innumerable calcifications throughout the parenchyma, partially calcified para pleural and para mediastinal line, subpleural cystic changes and calcified interlobular septa

\section{DISCUSSION}

Alveolar microlithiasis (AMP) was first reported by the Norwegian Harbitz in 1918; he described a rare disease characterized by the deposit of microliths intra-alveolar [4]. As a result, the disease was for a long time called "Harbitz syndrome", it was not until 1933 that the Hungarian Puhr named it pulmonary alveolar microlithiasis, a disease which results from an autosomal recessive transmission, without predominance significant gender. The countries with the majority of cases were Turkey, India, Italy, Japan and China [5]. 88.2\% of patients were diagnosed before age 50 compared to only $35.8 \%$ before age 20 according to the study by Mariotta et al., [6]. PAM is the result of several mutations involving the SLC34A2 gene [7]. This gene is also expressed in several extrapulmonary organs (kidneys, small intestine, pancreas, mammary glands, liver, ovaries, placenta, prostate and testes) but the disease does not no extrapulmonary manifestations [8]. The sodium phosphate cotransporter type IIb is responsible for the clearance of phospholipids in the alveoli, a mutation involving the SLC34A2 gene will be responsible for a dysfunction of this co-transporter and therefore an intra-alveolar aggregation of the calcium phosphate [9]. The disease exhibits a significant clinical polymorphism ranging from asymptomatic to respiratory failure. There is not enough information on the course of the disease due to the few cases reported in the literature. In some cases, MAP remains stable clinically and radiologically [1012]. The characteristic appearance on the chest $X$-ray is bilateral scattered calcified micronodular infiltrates more marked in the posterior middle and inferior regions giving the appearance of "sandstorm lung" hiding the mediastinal and diaphragmatic lines.During the course of the disease, on the chest CT scan, there is an accumulation of microliths in the pulmonary intestitum which gives the appearance of a calcified thickening of the subpleural space, of the peribronovascular space and the interlobular septa [13, 14-16].

The involvement on the chest CT scan is generally bilateral and symmetrical in the form of calcified micronodules more visible at the peripheral subpleural spaces, the mediastinal lines and interlobular septa giving the appearance of a stony lung. We can also assist with ground glass foci, consolidations 
containing dense calcifications and microcystic lesions $[13,14]$.

The differential diagnosis can be, talc granulomatosis, stannosis, and calcified miliary histoplasmosis but the lesions in this gender of these pathologies are of different distribution, larger, with respect for the subpleural spaces [17]. The impotant distribution; at the level of the lower and posterior regions as well as at the subpleural level, of the mediastinal and diaphrgamatic lines and the peribronchovascular spaces, is characteristic of MAP. Subpleural cysts generally ranging from 5 to $10 \mathrm{~mm}$ with a lead wall appear on a chest X-ray with a black pleural line. In MRI, Hoshino et al., demonstrated the appearance of PAM as diffuse calcified micronodules with increased signal intensity on T1-weighted images more pronounced in the lower and posterior regions [18].

PAM is generally a slowly progressive disease, although certain factors can make it even worse, such as infection and smoking [19].The measurement of the serum concentration of protein surfactant D and A has recently been shown to be useful in the diagnosis and monitoring of the disease [20].

Oxygenation and vaccination against influenza and pneumococcus are part of the management of MAP [18].

The disease has a poor prognosis, no effective treatment available, lung transplantation remains the only option in the advanced stage of the disease without noticeable recurrence, bronchoalveolar lavage and corticosteroids have not been shown to be effective. Currently disodium etidronate has been shown to be useful but research needs to be done to demonstrate its benefit. Gene therapy is also found to be useful in the future [21-27].

\section{Conclusion}

Alveolar microlithiasis (AMP) is a rare genetic disease. High resolution chest CT scan with chest X-ray make it possible to diagnose this disease with a pathognomonic appearance in the form of diffuse calcified micronodules.

\section{REFERENCES}

1. Castellana G, Castellana G, Gentile M, Castellana R, Resta O. Pulmonary alveolar microlithiasis: review of the 1022 cases reported worldwide. European respiratory review. 2015 Dec 1;24(138):607-20.

2. Helbich TH, Wojnarovsky C, Wunderbaldinger P, Heinz-Peer G, Eichler I, Herold CJ. Pulmonary alveolar microlithiasis in children: radiographic and high-resolution CT findings. AJR. American journal of roentgenology. 1997 Jan;168(1):63-5.
3. Gasparetto EL, Tazoniero P, Escuissato DL, Marchiori E, Frare e Silva RL, Sakamoto D. Pulmonary alveolar microlithiasis presenting with crazy-paving pattern on high resolution $\mathrm{CT}$. The British journal of radiology. 2004 Nov;77(923):974-6.

4. Harbitz E. Extensive calcification of the lungs as a distinct diseases. Arch Intern Med. 1918;21:139 46.

5. Castellana G, Castellana G, Gentile M, Castellana R, Resta O. Pulmonary alveolar microlithiasis: review of the 1022 cases reported worldwide. European respiratory review. 2015 Dec 1;24(138):607-20.

6. Mariotta S, Guidi L, Papale M, Ricci A, Bisetti A. Pulmonary alveolar microlithiasis: review of Italian reports. European journal of epidemiology. 1997 Jul;13(5):587-90.

7. Yin X, Wang H, Wu D, Zhao G, Shao J, Dai Y. SLC34A2 gene mutation of pulmonary alveolar microlithiasis: report of four cases and review of literatures. Respiratory medicine. 2013 Feb 1;107(2):217-22.

8. Takahashi H, Chiba H, Shiratori M, Tachibana T, Abe S. Elevated serum surfactant protein A and D in pulmonary alveolar microlithiasis. Respirology. 2006 May;11(3):330-3.

9. Khaladkar SM, Kondapavuluri SK, Kamal A, Kalra R, Kuber RS. Pulmonary alveolar microlithiasis - clinico-radiological dissociation a case report with radiological review. J Radiol Case Rep. 2016;10(1):1-21

10. Mascie-Taylor BH, Wardman AG, Madden CA, Page RL. A case of alveolar microlithiasis: Observation over 22 years and recovery of material by lavage. Thorax. 1985;40:952-3.

11. Moran CA, Hochholzer L, Hasleton PS, Johnson FB, Koss MN. Pulmonary alveolar microlithiasis. A clinicopathologic and chemical analysis of seven cases. Arch Pathol Lab Med. 1997;121:60711

12. Mariotta S, Ricci A, Papale M. Pulmonary alveolar microlithiasis: report on 576 cases published in the literature. Sarcoidosis Vasc Diffuse Lung Dis. 2004;21:173-181.

13. Huqun, Izumi S, Miyazawa H, Ishii K, Uchiyama B, Ishida T. Mutations in the SLC34A2 gene are associated with pulmonary alveolar microlithiasis. Am J Respir Crit Care Med. 2007;175:263-8.

14. Sumikawa H, Johkoh T, Tomiyama N, Hamada S, Koyama M, Tsubamoto M. Pulmonary alveolar microlithiasis: CT and pathologic findings in 10 patients. Monaldi Arch Chest Dis. 2005;63:5964.

15. Prakash UB. Pulmonary alveolar microlithiasis. Semin Respir Crit Care Med. 2002;23:103-13.

16. Deniz O, Ors F, Tozkoparan E, Ozcan A, Gumus S, Bozlar U. High resolution computed 
F. Jaafari et al., Sch J Med Case Rep, Mar, 2021; 9(3): 261-264

tomographic features of pulmonary alveolar microlithiasis. Eur J Radiol. 2005;55:452-60.

17. Felson B. Thoracic calcifications. Dis Chest. 1969;56:330-43.

18. Hoshino H, Koba H, Inomata S, Kurokawa K, Morita Y, Yoshida K. Pulmonary alveolar microlithiasis: High-resolution CT and MR findings. J Comput Assist Tomogr. 1998;22:2458.

19. Corut A, Senyigit A, Ugur SA, Altin S, Ozcelik U, Calisir H, Yildirim Z, Gocmen A, Tolun A. Mutations in SLC34A2 cause pulmonary alveolar microlithiasis and are possibly associated with testicular microlithiasis. The American Journal of Human Genetics. 2006 Oct 1;79(4):650-6.

20. Murer H, Forster I, Biber J. The sodium phosphate cotransporter family SLC34. Pflügers Archiv. 2004 Feb;447(5):763-7.

21. Tachibana T, Hagiwara K, Johkoh T. Pulmonary alveolar microlithiasis: review and management. Current opinion in pulmonary medicine. 2009 Sep 1;15(5):486-90.

22. Ozcelik U, Yalcin E, Arıyurek M, Ersoz DD, Cinel G, Gulhan B, Kiper N. Long- term results of disodium etidronate treatment in pulmonary alveolar microlithiasis. Pediatric pulmonology. 2010 May;45(5):514-7.
23. Cakir E, Gedik AH, Özdemir A, Buyukpınarbasili $\mathrm{N}$, Bilgin M, Ozgen IT. Response to disodium etidronate treatment in three siblings with pulmonary alveolar microlithiasis. Respiration. 2015;89(6):583-6.

24. Göcmen A, Toppare MF, Kiper N, Büyükpamukcu N. Treatment of pulmonary alveolar microlithiasis with a diphosphonatepreliminary results of a case. Respiration. 1992;59(4):250-2.

25. Stamatis G, Zerkowski HR, Doetsch N, Greschuchna D, Konietzko N, Reidemeister JC. Sequential bilateral lung transplantation for pulmonary alveolar microlithiasis. The Annals of thoracic surgery. 1993 Oct 1;56(4):972-5.

26. Klikovits T, Slama A, Hoetzenecker K, Waseda R, Lambers C, Murakoezy G, Jaksch P, Aigner C, Taghavi S, Klepetko W, Lang G. A rare indication for lung transplantation-pulmonary alveolar microlithiasis: institutional experience of five consecutive cases. Clinical transplantation. 2016 Apr;30(4):429-34.

27. Shigemura N, Bermudez C, Hattler BG, Johnson B, Crespo M, Pilewski J, Toyoda Y. Lung transplantation for pulmonary alveolar microlithiasis. The Journal of thoracic and cardiovascular surgery. 2010 Mar 1;139(3):e50-2. 